\title{
Synergy of entry inhibitors with direct-acting antivirals uncovers novel combinations for prevention and treatment of hepatitis $\mathrm{C}$
}

\author{
Fei Xiao, ${ }^{1,2}$ Isabel Fofana, ${ }^{1,2}$ Christine Thumann, ${ }^{1,2}$ Laurent Mailly, ${ }^{1,2}$ \\ Roxane Alles, ${ }^{1,2,3}$ Eric Robinet, ${ }^{1,2}$ Nicolas Meyer, ${ }^{4}$ Mickaël Schaeffer, ${ }^{4}$ \\ François Habersetzer, ${ }^{1,2,5}$ Michel Doffoël, ${ }^{1,2,5}$ Pieter Leyssen, ${ }^{6}$ Johan Neyts, ${ }^{6}$ \\ Mirjam B Zeisel, ${ }^{1,2}$ Thomas F Baumert ${ }^{1,2,5,7}$
}

- Additional material is published online only. To view please visit the journal online (http://dx.doi.org/10.1136/ gutjnl-2013-306155).

${ }^{1}$ Inserm, U1110, Strasbourg, France

${ }^{2}$ Université de Strasbourg, Strasbourg, France

${ }^{3}$ Inserm, U977, Strasbourg, France

${ }^{4}$ Pôle de Santé Publique, Centre Hospitalier Régional Universitaire de Strasbourg, Strasbourg, France ${ }^{5}$ Pôle Hépato-digestif, Hôpitaux Universitaires de Strasbourg, Strasbourg, France

${ }^{6}$ Rega Institute for Medical Research, KULeuven, Leuven, Belgium

${ }^{7}$ Gastrointestinal Unit, Massachusetts General Hospital, Harvard Medical School, Boston, USA

\section{Correspondence to}

Professor Thomas F Baumert, Inserm Unit 1110, Université de Strasbourg, 3 rue Koeberlé, Strasbourg F-67000, France;

Thomas.Baumert@unistra.fr

FX and IF contributed equally.

Received 2 October 2013 Revised 20 March 2014 Accepted 8 April 2014

Published Online First

21 May 2014

\section{SLinked}

- http://dx.doi.org/10.1136/ gutjnl-2014-307452

\section{CrossMark}

To cite: Xiao F, Fofana I, Thumann C, et al. Gut 2015;64:483-494.

\section{ABSTRACT}

Objective Although direct-acting antiviral agents

(DAAs) have markedly improved the outcome of

treatment in chronic HCV infection, there continues to be an unmet medical need for improved therapies in difficult-to-treat patients as well as liver graft infection. Viral entry is a promising target for antiviral therapy. Design Aiming to explore the role of entry inhibitors for future clinical development, we investigated the antiviral efficacy and toxicity of entry inhibitors in combination with DAAs or other host-targeting agents (HTAs). Screening a large series of combinations of entry inhibitors with DAAs or other HTAs, we uncovered novel combinations of antivirals for prevention and treatment of HCV infection. Results Combinations of DAAs or HTAs and entry inhibitors including CD81-, scavenger receptor class B type I (SR-BI)- or claudin-1 (CLDN1)-specific antibodies or small-molecule inhibitors erlotinib and dasatinib were characterised by a marked and synergistic inhibition of HCV infection over a broad range of concentrations with undetectable toxicity in experimental designs for prevention and treatment both in cell culture models and in human liver-chimeric uPA/SCID mice.

Conclusions Our results provide a rationale for the development of antiviral strategies combining entry inhibitors with DAAs or HTAs by taking advantage of synergy. The uncovered combinations provide perspectives for efficient strategies to prevent liver graft infection and novel interferon-free regimens.

\section{INTRODUCTION}

The current standard of care (SOC) in chronic genotype $1 \mathrm{HCV}$ infection consists of pegylated IFN- $\alpha$, ribavirin (RBV) and a protease inhibitortelaprevir or boceprevir. ${ }^{1-3}$ Furthermore, direct-acting antivirals (DAAs) sofosbuvir and simeprevir have been licensed very recently. Although expected to revolutionise HCV treatment by offering cure in the very large majority of treated patients, ${ }^{4}$ DAAs appear to have distinct limitations in certain difficult-to-treat patient subgroups, such as patients with advanced liver disease, transplant, $\mathrm{HIV} / \mathrm{HCV}$-coinfected and immune-compromised patients. ${ }^{2}$ Hurdles in these groups include resistance and side effects. ${ }^{2}{ }^{4}$ Furthermore, not all genotypes respond similar to DAA combinations and

\section{Significance of this study}

What is already known on this subject?

- Direct-acting antivirals (DAAs) increase the response to IFN-based antiviral therapy against HCV genotype 1 but also lead to selection of drug-resistant HCV variants.

- Given their important side effects and drugdrug interactions, DAAs against HCV are not approved for patients undergoing liver transplantation (LT), HCV/HIV coinfected patients or paediatric patients.

- Although early clinical trials have demonstrated impressive outcomes for combinations of DAAs in IFN-free regimens for treatment-naive patients, there will be a need for novel antivirals addressing resistance, treatment of patients with comorbidity, co-medication or immunosuppression and patients undergoing LT.

- HCV entry into target cells is a promising target for preventive and therapeutic antiviral strategies.

\section{What are the new findings?}

- Given their complementary mechanism of action, entry inhibitors inhibit viral infection in a synergistic manner in combination with DAAs both in cell culture models and in human liver-chimeric UPA/SCID mice.

- Synergy between entry inhibitors and DAAs or other host-targeting agents holds promise for a variety of possibilities of combination therapies for prevention of HCV liver graft infection and might be also useful for treatment of hepatitis $C$.

How might it impact on clinical practice in the foreseeable future?

- Novel combinations based on synergy may widen the therapeutic arsenal against HCV infection for prevention of liver graft infection, treatment of difficult-to-treat-patients and provide alternatives for patients with contraindications to particular compounds of standard of care or future IFN-free regimens. 
high costs limit access to therapy in low-income, middle-income and high-income countries. ${ }^{2} 4$

Among the most difficult-to-treat patient groups are individuals with HCV-induced end-stage liver disease undergoing liver transplantation (LT). ${ }^{1}{ }^{2}$ Due to viral evasion from host immune responses and absence of preventive antiviral strategies, graft reinfection is universal. Moreover, IFN-based therapies have limited efficacy and tolerability in LT recipients. ${ }^{5}$ The use of telaprevir and boceprevir is limited by drug-drug interactions if combined with immunosuppressive agents. ${ }^{6} 7$ Furthermore, emergence of resistant strains will certainly be higher in these patients because of lower efficacy of SOC and greater need for dose adjustments. ${ }^{5}$ These challenges define a need for additional combinations of therapeutics, ideally targeting complementary steps of the viral life cycle, with improved efficacy and safety.

A promising antiviral target complementary to targets of SOC and DAAs is viral cell entry. HCV entry is the first step of virushost cell interactions and is required for dissemination and maintenance of infection. ${ }^{8}$ Viral entry plays an important role in the pathogenesis of HCV infection, especially during HCV reinfection of the graft after LT. ${ }^{10}$ Targets for entry inhibitors include CD81, scavenger receptor class B type I (SR-BI), tight junction proteins CLDN1 and occludin, epidermal growth factor receptor (EGFR) ${ }^{8} 11$ and Nieman-Pick C1-Like $1 .^{12}$ Entry inhibitors exhibit a broad pan-genotypic activity. ${ }^{10}{ }^{12-21}$ By acting through a complementary mechanism of action (MOA), entry inhibitors may synergistically act with SOC. To explore the future application of entry inhibitors for combination therapy in IFN-free regimens, we investigated the antiviral efficacy of entry inhibitors in combination with DAAs or other host-targeting agents (HTAs) in state-of-the-art cell culture models and in human liver-chimeric uPA/SCID mice.

\section{MATERIAL AND METHODS \\ Cell lines}

Huh7.5.1 cells and primary human hepatocyte $(\mathrm{PHH})$ culture have been described. ${ }^{13}$

\section{Antibodies and inhibitors}

CLDN1- (OM-7D3-B3), ${ }^{22}$ SR-BI- (NK-8H5-E3) ${ }^{14}$ and CD81specific (QV-6A8-F2C4) ${ }^{16}$ monoclonal antibodies (mAbs) have been described. Erlotinib and dasatinib were from LC Laboratories, and IFN- $\alpha 2 a$ and IFN- $\alpha 2 b$ were from Roche and Merck. Alisporivir, telaprevir, boceprevir, danoprevir, simeprevir, daclatasvir, mericitabine and sofosbuvir were synthesised by Acme Bioscience.

\section{Analysis of antiviral activity of compounds and combinations on HCV infection}

Each compound was tested individually or in combination with a second compound using the cell culture-derived $\mathrm{HCV}$ (HCVcc)-Huh7.5.1 model. ${ }^{14}{ }^{23}$ Production of HCVcc has been described. ${ }^{13}$ For prophylactic/prevention combination experiments, Huh7.5.1 cells were preincubated with IFN- $\alpha$, DAAs or HTAs for $1 \mathrm{~h}$ at $37^{\circ} \mathrm{C}$ before incubation for $4 \mathrm{~h}$ at $37^{\circ} \mathrm{C}$ with $\mathrm{HCVcc}$ and both compounds. For therapeutic/treatment combination experiments, Huh7.5.1 cells were infected with HCVcc during 5 days to establish chronic persistent $\mathrm{HCV}$ infection before adding compounds for additional 5 days. ${ }^{23}$ Viral infection was analysed by assessing luciferase activity. ${ }^{10} 1322$

\section{Analysis of synergy}

Synergy was assessed by two independent methods: the combination index $(\mathrm{CI})^{24}$ and/or the Prichard and Shipman method. ${ }^{25}$
A CI $<0.9,0.9-1.1$ and $>1.1$ indicates synergy, an additive effect and antagonism, respectively. ${ }^{24}$ For the Prichard and Shipman method, a surface $>20 \%$ above the zero plane indicates synergy and a surface $<20 \%$ below the zero plane indicates antagonism. ${ }^{25}$ Validity of the assay and methods was confirmed by non-synergistic or antagonistic combinations.

\section{HCV cell culture persistence assay}

HCV RNA (Jc1 or Luc-Jc1) was electroporated into Huh7.5.1 cells to establish persistent HCV infection. Then, 1\% DMSO was used to differentiate the cells and maintain them in culture without passage for up to 20 days. ${ }^{26}$ Medium containing compounds at the indicated concentrations was replenished every 4-5 days until the end of the experiment. Luciferase activity or RT-PCR was used to monitor viral infection and viral load. ${ }^{27}$

\section{In vivo experimentation}

Human liver-chimeric uPA/SCID mice were transplanted with $\mathrm{PHH}$ at 3 weeks of age by intrasplenic injection of $10^{6}$ cells suspended in PBS as described previously. ${ }^{28}$ Successful engraftment was determined by measuring the human albumin (HA) concentration in the serum of transplanted mice by specific ELISA (Bethyl, Catalogue No. E80-129). Mice with HA levels $>1 \mathrm{mg} / \mathrm{mL}$ were used for IV inoculation with HCV Jc1-containing infectious mouse serum $\left(6 \times 10^{3} \mathrm{IU}\right)$. Eight weeks later, the mice were allocated to different treatment groups. Mice received telaprevir $(300 \mathrm{mg} / \mathrm{kg}$ ) or vehicle (carboxymethylcellulose $0.5 \%$, tween- 80 $0.2 \%)$ per os twice a day and were intraperitoneally injected with $500 \mu \mathrm{g}$ of control or anti-SR-BI mAb (NK8-H5-E3) twice a week for 2 weeks. Blood was collected by retro-orbital puncture every 5-10 days under isoflurane anaesthesia for the determination of serum HCV RNA level and HA concentration. Experiments were performed in the Inserm Unit 1110 animal facility according to local laws and ethical committee approval (AL/02/19/08/12 and AL/01/18/08/12).

\section{Toxicity assays}

Huh7.5.1 cells and PHH were incubated with compounds for $48 \mathrm{~h}$ and/or 5 days. $^{22}{ }^{23}$ Cytotoxic effects were analysed using MTT (3-(4,5-dimethylthiazol-2-yl)-2,5-diphenyltetrazolium bromide) assay ${ }^{13} 22$ or PrestoBlue assay (Invitrogen) with flavopiridol or anti-Fas antibody as positive controls. ${ }^{22}$ The $50 \%$ cytotoxic concentrations $\left(\mathrm{CC}_{50}\right)$ of entry inhibitors were calculated by regression analysis.

\section{Statistical analysis}

Statistical analysis and CI estimations have been run under Bayesian paradigm. Results are given as mean and (95\% credible interval). Data were analysed by IC (50/75/90). Group comparisons were based on the mean difference. Normality was assessed with a Shapiro-Wilk test. When required, data transformation was used to reach normality. Each data set was analysed using hierarchical (mixed) model with fixed group effects and random treatment effect as described. ${ }^{29}$ The whole data set was analysed using a two-stage hierarchical model, with the fixed group effects and two random effects that were treatment and IC (50/ $75 / 90)$, in order to take account of both levels of repeated measurements. Dummy variables, representing the IC studied (50/ 75/90), had also been considered as fixed effects to test differences between CI in each case. For all of these models, uninformative priors for coefficients were used: Gaussian distributions with mean 0 and precision 0.001 , gamma distribution with parameters 0.1 and 0.1 for the model precision. 
Hyperpriors for random effects were also uninformative: normal with mean 0 and precision 0.001 , and a uniform distribution $(0.100)$ for dispersion parameters. Assumption of homogeneous dispersions in random effects was respected. Computations were run with R 3.00 and WinBUGS 1.4. For each analysis, a single MCMC chain with 5000 iterations as burn-in and 100000 iterations was used to generate the posterior distribution. Convergence was checked and present in every case. Unless otherwise stated, results are shown as means \pm SEM from three independent experiments performed in triplicate. For the Prichard and Shipman method, one representative experiment performed in triplicate is shown.

\section{RESULTS}

\section{Synergy of entry inhibitors and DAAs uncovers novel} combinations for IFN-free regimens

A major effort of current drug development is to develop IFN-free treatments based on the combination of DAAs with or without RBV. ${ }^{1}$ Addressing these concepts, we studied the combined antiviral effect of entry inhibitors with clinically licensed protease inhibitors telaprevir, ${ }^{30} 31$ boceprevir, ${ }^{32} 33$ simeprevir ${ }^{34}$ and danoprevir-a protease inhibitor in late-stage clinical development $^{35}$ using the HCVcc cell culture model. The antiviral effect of each molecule was tested alone or in combination to determine the CI. Combination of telaprevir or boceprevir with a sub- $\mathrm{IC}_{50}$ concentration of all entry inhibitors tested-which exerts only minimal inhibition on $\mathrm{HCV}$ infection-resulted in synergy with CIs of $0.48-0.71$ at IC $_{90}$ (figure $1 \mathrm{~A}$ and online supplementary table S1). Calculation of $95 \%$ credible intervals indicates that the differences between CI values did not occur by chance (figure $1 \mathrm{~A}$ and online supplementary table S1). Synergy was also observed at $\mathrm{IC}_{50}$ and $\mathrm{IC}_{75}$ (figure $1 \mathrm{~A}$ and online supplementary table S1). Inversely, combination of telaprevir and boceprevir was additive (CI of $0.94,95 \%$ credible interval ( 0.84 to 1.04 ); figure $1 \mathrm{~A})$ confirming the validity of the assay. Combination of simeprevir or danoprevir with entry inhibitors resulted in synergy at all inhibitory concentrations (CIs of 0.06 to 0.65 at $\mathrm{IC}_{90}$; figure $1 \mathrm{~A}$ and online supplementary table S1), demonstrating the relevance of adding an entry inhibitor to improve antiviral efficacy in preventing HCV infection. Highly effective combinations included inter-alia combinations of telaprevir with erlotinib (figure $2 \mathrm{~A}$ ), and boceprevir or simeprevir with anti-CLDN1 mAb (figure 2B, C).

A number of NS5A and polymerase inhibitors have reached early-stage to late-stage clinical development including clinical licensing of the first compounds. As the first NS5A inhibitor, daclatasvir $^{36}$ has shown potent antiviral activity against HCV genotype 1 in mono- and combination therapy. ${ }^{37}$ Marked synergy at all inhibitory concentrations was observed for combination of daclatasvir with entry inhibitors (CIs of $0.27-0.89$ at $\mathrm{IC}_{90}$; figure $1 \mathrm{~B}$, online supplementary table $\mathrm{S} 1 \mathrm{C}$ ). Effective combinations included inter-alia combinations of daclatasvir and anti-SR-BI, anti-CLDN1 mAbs or erlotinib decreasing its $\mathrm{IC}_{50}$ up to 60 -fold (figure $3 \mathrm{~A}-\mathrm{C}$ ).
Figure 1 Combination of direct-acting antivirals and entry inhibitors results in a synergistic activity in preventing HCV infection. Huh7.5.1 cells were preincubated for $1 \mathrm{~h}$ with serial concentrations of $(\mathrm{A})$ telaprevir, boceprevir, simeprevir or danoprevir, (B) daclatasvir or (C) mericitabine or sofosbuvir and $0.01 \mu \mathrm{g} / \mathrm{mL}$ of receptor-specific (anti-CD81, anti-SR-BI or anti-CLDN1) $\mathrm{mAbs}$ or $0.1 \mu \mathrm{M}$ protein kinase inhibitors (erlotinib or dasatinib) before incubation with HCV CC Luc-Jc1 in the presence of both compounds. HCVcc infection was analysed by luciferase activity as described. ${ }^{22}$ The $\mathrm{Cls}$ at $\mathrm{IC}_{50}$, $I C_{75}$ and $I C_{90}$ are indicated in online supplementary table $\mathrm{S1}$. Means $\pm 95 \%$ credible intervals from three independent experiments performed in triplicate are shown.

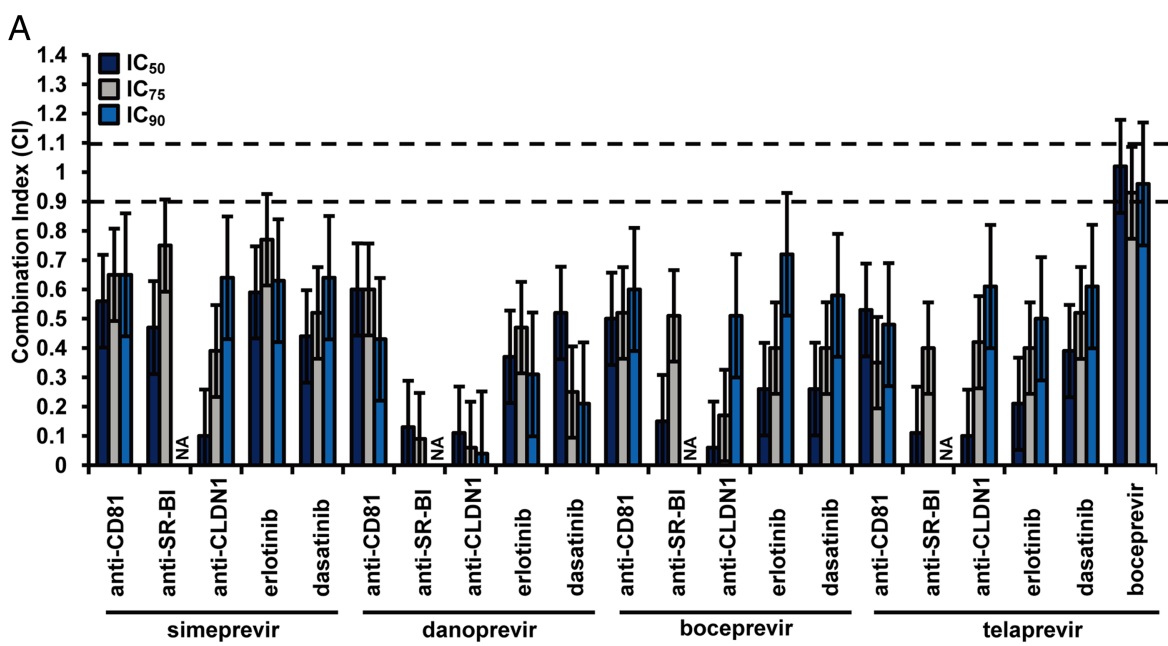

B

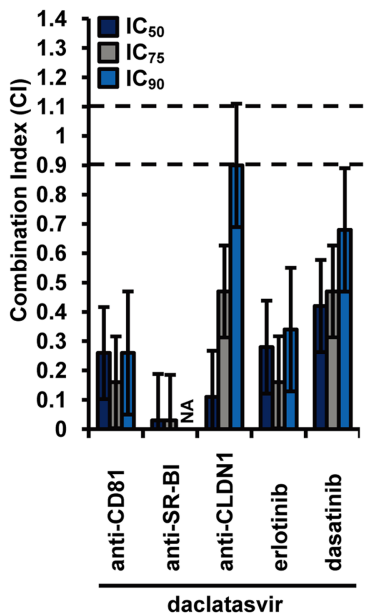

C

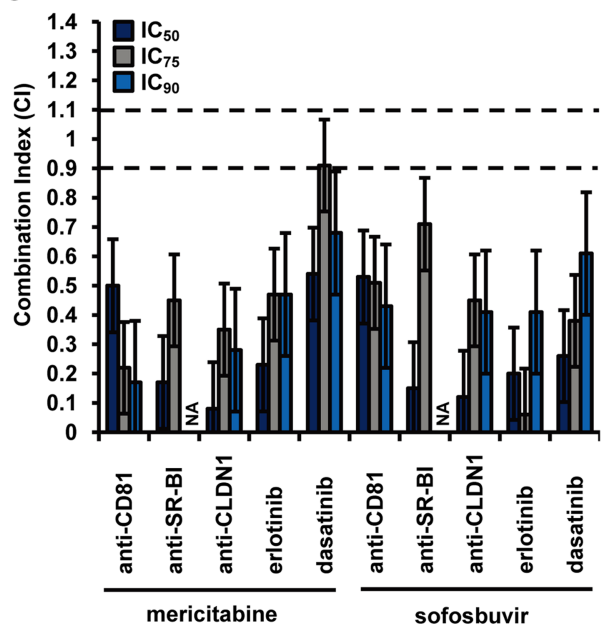




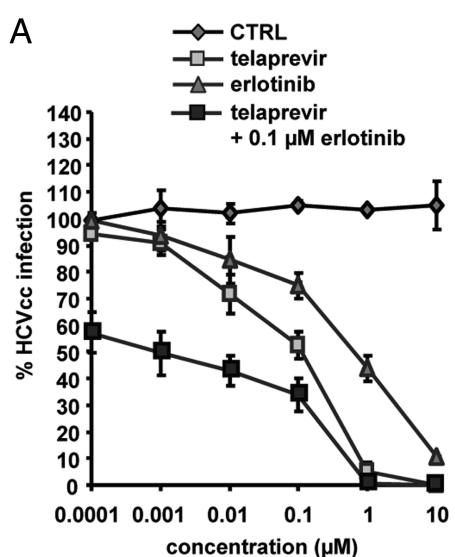

D

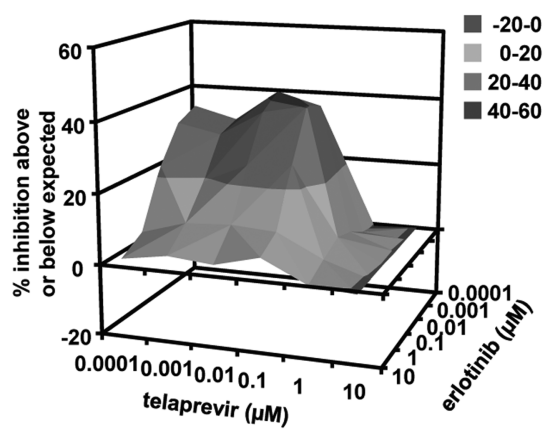

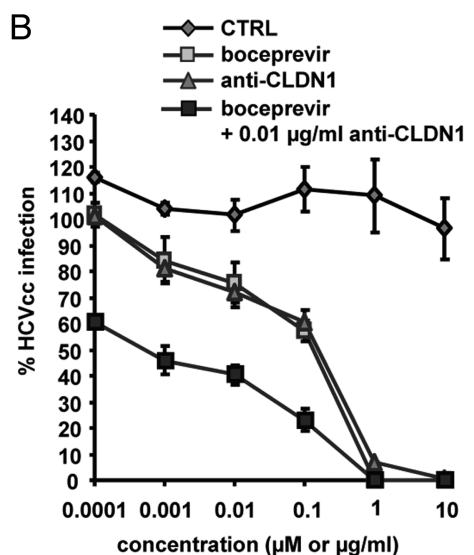

$\mathrm{E}$

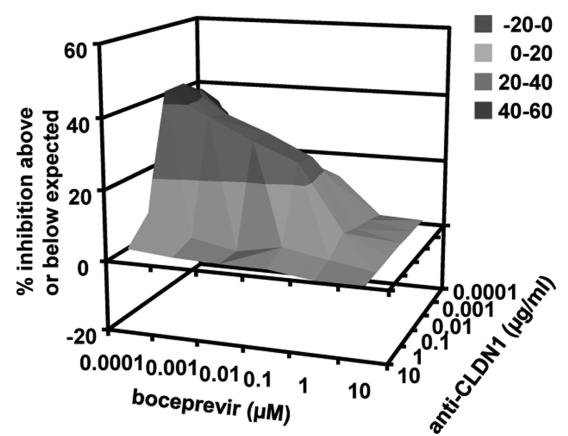

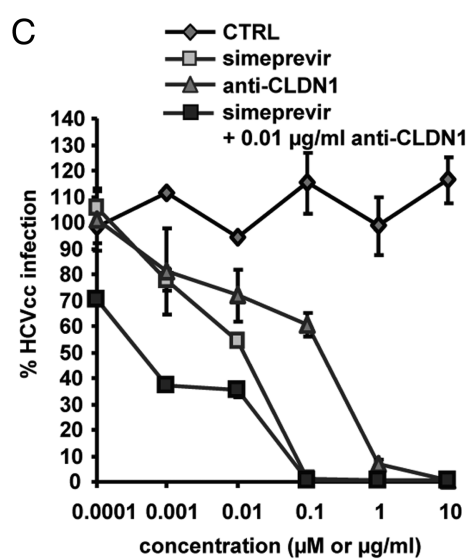

$\mathrm{F}$

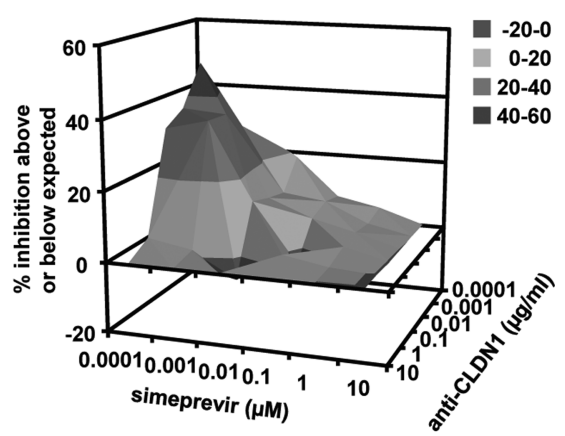

Figure 2 Antiviral synergy of entry and protease inhibitors. Combination (A) telaprevir and erlotinib, (B) boceprevir or (C) simeprevir and anti-CLDN1 mAb was performed as described in figure 1. (D-F) Synergy was confirmed using the Prichard and Shipman method. ${ }^{25}$

Finally, we investigated synergy between entry inhibitors and the polymerase inhibitor sofosbuvir, ${ }^{39}$ which recently obtained FDA approval and has the potential to become the cornerstone for an efficacious, all-oral combination regimen for many HCV-infected patients. ${ }^{40}{ }^{41}$ Combination of sofosbuvir with entry inhibitors resulted in synergy at all inhibitory concentrations (CIs of $0.41-0.61$ at $\mathrm{IC}_{90}$; figure $1 \mathrm{C}$, figure $4 \mathrm{~A}, \mathrm{~B}, \mathrm{D}, \mathrm{E}$ and online supplementary table S1). Potent combinations included inter-alia combinations of sofosbuvir and anti-SR-BI or anti-CLDN1 mAbs, decreasing its IC $_{50}$ up to 18 -fold, and combinations of sofosbuvir with erlotinib or dasatinib decreasing its $\mathrm{IC}_{50}$ up to 210 -fold (figure $\left.4 \mathrm{~A}, \mathrm{~B}, \mathrm{D}, \mathrm{E}\right)$. These data demonstrate the potential of combining sofosbuvir with entry inhibitors to improve its antiviral activity. Similar results were obtained when combining mericitabine ${ }^{35}$ with entry inhibitors (CIs of $0.18-$ 0.68 at $\mathrm{IC}_{90}$; figure $1 \mathrm{C}$ and online supplementary table $\mathrm{S} 1$ ).

To further confirm synergy over a broad range of concentrations of two compounds, we performed combinations of each DAA with a defined entry inhibitor, testing a full checkerboard of compound dose-response curves. ${ }^{25}$ In particular, combinations of low doses of two compounds resulted in an antiviral effect well above the expected value (figures 2D-F, 3D-F and $4 \mathrm{C}, \mathrm{F})$. These results demonstrate that adding an entry inhibitor markedly increases the antiviral activity of different DAAs currently evaluated in IFN-free regimens, thereby defining novel antiviral combinations for further preclinical and clinical development in IFN-free regimens.

\section{Combination of HTAs results in a synergistic antiviral effect}

It is still not clear whether DAA-based therapies will be effective and safe in difficult-to-treat populations including patients with comorbidity, complex co-medication, immunosuppression and patients undergoing LT. Combinations of HTAs are a promising alternative to DAAs for IFN-sparing regimens, allowing increasing the genetic barrier to resistance. The clinically most advanced HTA is cyclophilin A inhibitor alisporivir. ${ }^{42}$ Combination of alisporivir with entry inhibitors resulted in a marked synergy (CIs of $0.19-0.69$ at $\mathrm{IC}_{75}$ and $0.06-0.50$ at $\mathrm{IC}_{50}$; figure $5 \mathrm{D}$ and online supplementary table S2). Effective combinations included inter-alia alisporivir and erlotinib or anti-CLDN1 $\mathrm{mAb}$ (figure 5E). Indeed, very low concentrations of these entry inhibitors markedly increased the antiviral effect of alisporivir by decreasing its $\mathrm{IC}_{50}$ up to 3000 -fold. Synergy of alisporivir and anti-CLDN1 mAb was confirmed using the Prichard and Shipman method (figure 5F). Taken together, these data demonstrate the promise of combining HTAs acting on complementary steps of the viral life cycle and open perspectives for HTA-based DAA or IFN-free regimens. These combinations may be of particular interest for/to patients who are resistant to SOC, or cannot tolerate SOC or combinations of DAAs. Furthermore, combinations of two entry inhibitors resulted in synergy on $\mathrm{HCV} c \mathrm{infection}$ at all inhibitory concentrations (CIs of $0.13-0.68$ at $\mathrm{IC}_{90}$; figure $5 \mathrm{~A}-\mathrm{C}$ and online supplementary table S2) except for combination of anti-CLDN1 and anti-CD81 mAbs that resulted in an additive effect (CI of $0.95,95 \%$ credible interval $(0.85-1.06)$ at $\mathrm{IC}_{90}$; figure $\left.5 \mathrm{~A}\right)$.

Entry inhibitors potentiate the antiviral activity of IFN- $\alpha$ in a synergistic manner

Since IFN- $\alpha$ is the key component of current SOC, we also investigated whether HCV entry inhibitors potentiate the antiviral activity of IFN- $\alpha$ by combining an entry inhibitor with 


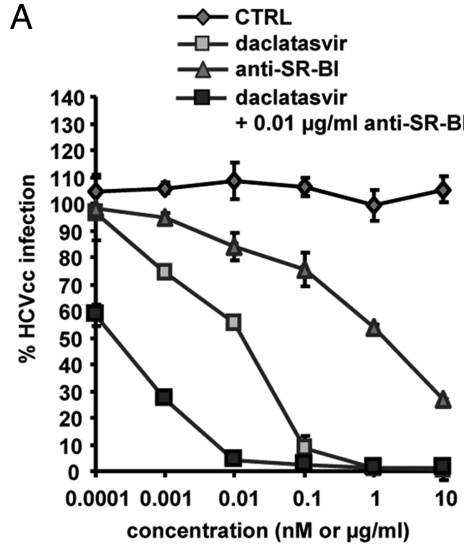

D

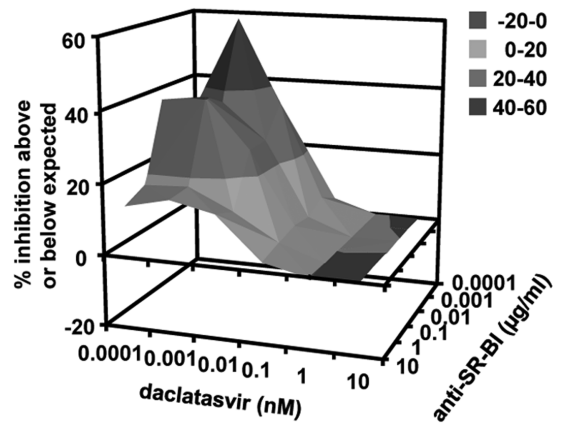

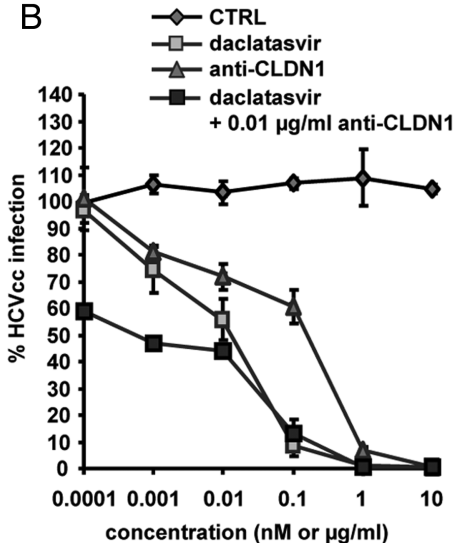

$E$

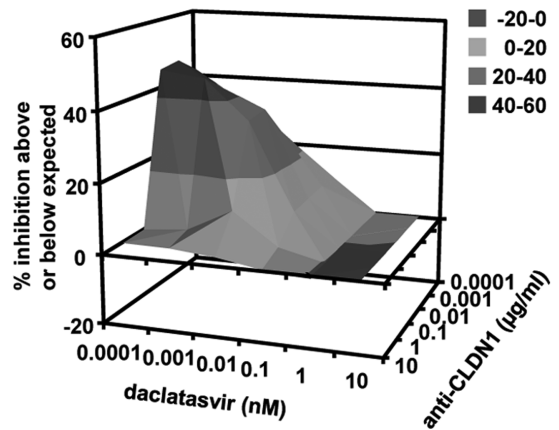

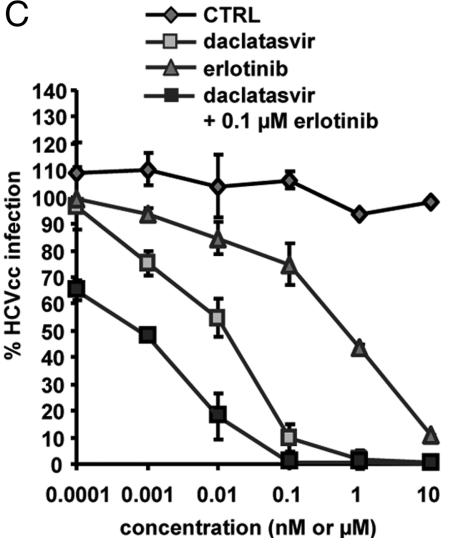

$\mathrm{F}$

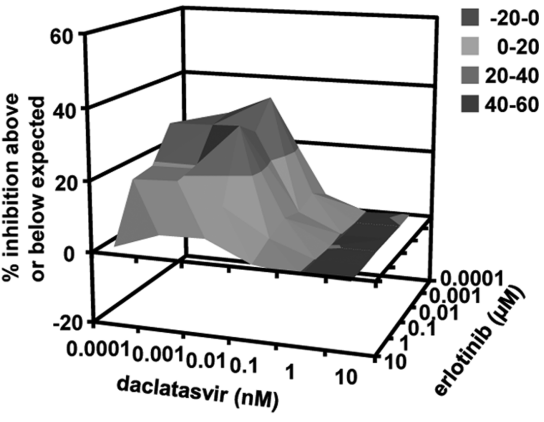

Figure 3 Synergy of entry inhibitors and daclatasvir. Combination of daclatasvir and (A) anti-SR-BI mAb, (B) anti-CLDN1 mAb or (C) erlotinib was performed as described in figure 1. (D-F) Synergy was confirmed using the Prichard and Shipman method. ${ }^{25}$


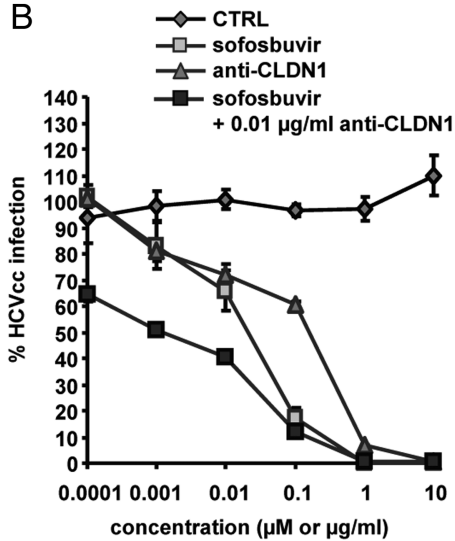

E

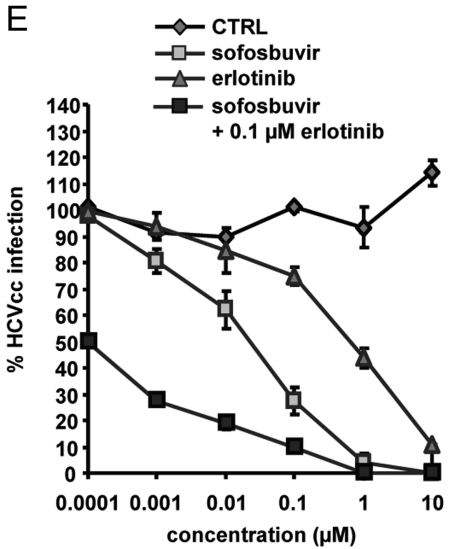

C

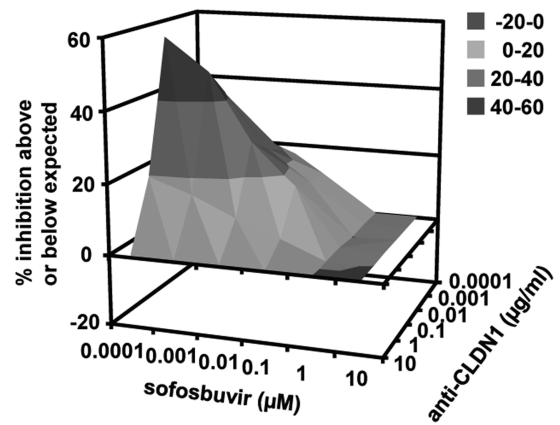

$\mathrm{F}$

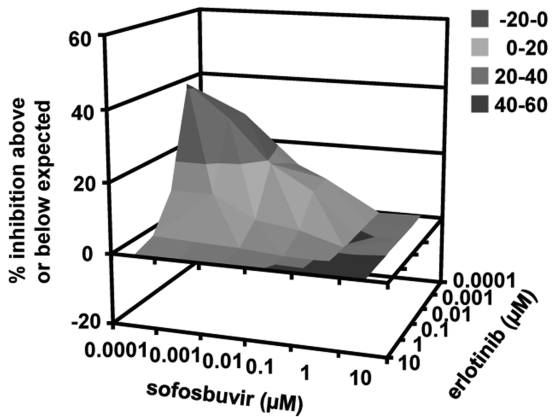

Figure 4 Entry inhibitors enhance the antiviral activity of sofosbuvir in a synergistic manner. Combination of sofosbuvir and (A) anti-SR-BI mAb, (B) anti-CLDN1 mAb, (D) dasatinib or (E) erlotinib was performed as described in figure 1. (C, F) Synergy was confirmed using the Prichard and Shipman method. ${ }^{25}$ 

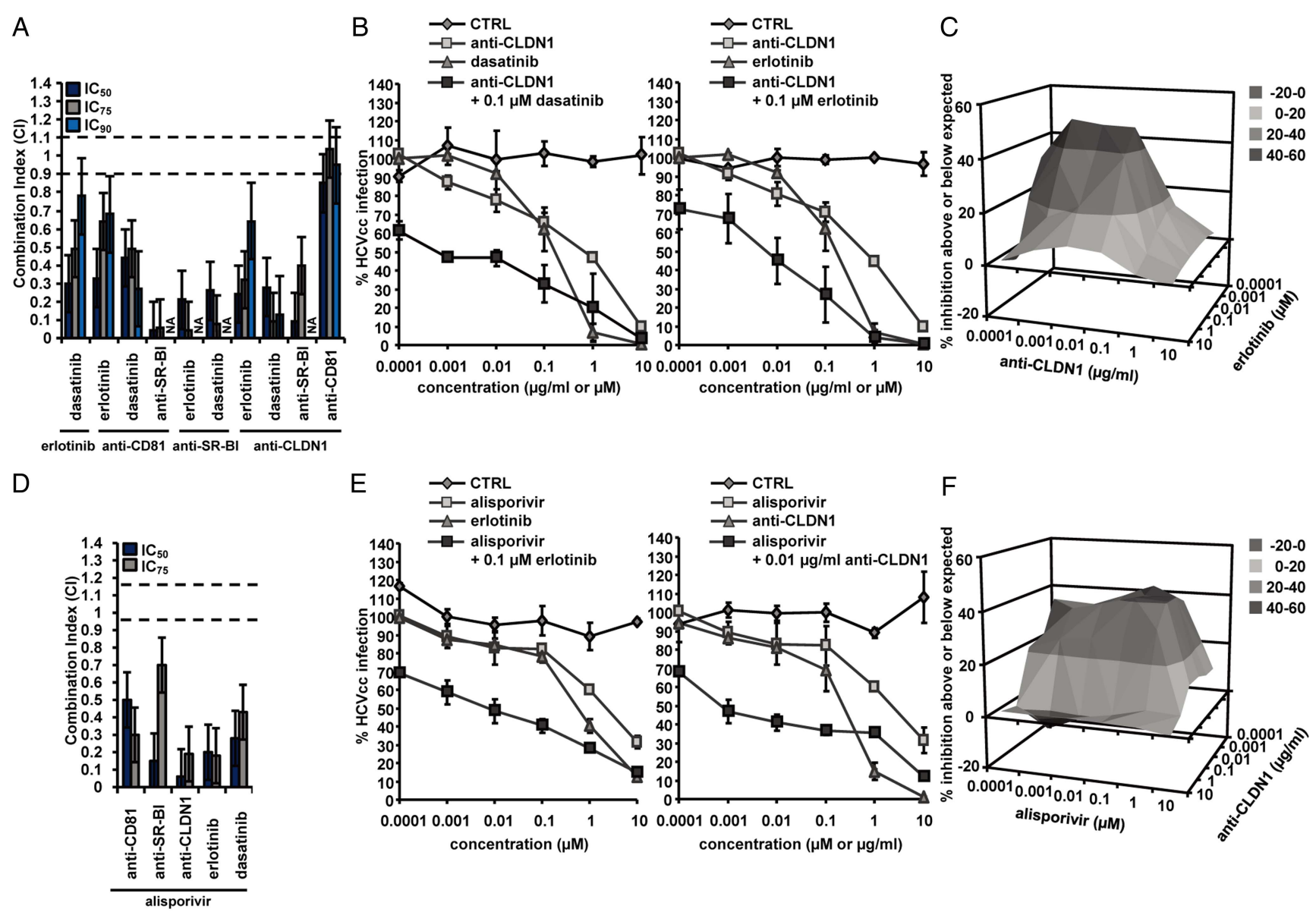

Figure 5 Synergy of host-targeting agents on HCV infection. (A) Combination of receptor-specific (anti-CD81, anti-SR-BI or anti-CLDN1) mAbs and protein kinase inhibitors (erlotinib or dasatinib) was performed as described in figure 1 and the $\mathrm{Cls}_{\mathrm{s}} \mathrm{IC} \mathrm{C}_{50}, \mathrm{IC}_{75}$ and $I \mathrm{C}_{90}$ are indicated in online supplementary table $\mathbf{S} 2$. Means $\pm 95 \%$ credible intervals from three independent experiments performed in triplicate are shown. (B) Combination of anti-CLDN1 mAb and dasatinib (left) or erlotinib (right). (C) Synergy was confirmed using the Prichard and Shipman method. ${ }^{25}$ (D) Combination of alisporivir and entry inhibitors was performed as described in figure 1 and the $\mathrm{Cls}$ at $\mathrm{IC}_{50}, \mathrm{IC}_{75}$ and IC 90 are indicated in online supplementary table S2. Means $\pm 95 \%$ credible intervals from three independent experiments performed in triplicate are shown. (E) Combination of alisporivir with erlotinib (left) or anti-CLDN1 mAb (right). (F) Synergy was confirmed using the Prichard and Shipman method. ${ }^{25}$

IFN- $\alpha 2 a$ or IFN- $\alpha 2 b$. Combination of IFN- $\alpha 2 a$ or IFN- $\alpha 2 b$ with a sub-IC $\mathrm{IC}_{50}$ concentration of receptor-specific $\mathrm{mAb}$ resulted in a synergistic activity at $\mathrm{IC}_{90}$ in inhibiting $\mathrm{HCV} c c$ infection (CIs of 0.16-0.53) (see online supplementary figure S1 and table S3). Synergy combining IFN- $\alpha 2$ a or IFN- $\alpha 2 b$ with erlotinib has been described elsewhere. ${ }^{23}$ Synergy was also observed at $\mathrm{IC}_{50}$ and $\mathrm{IC}_{75}$ for all combinations tested (see online supplementary figure S1 and table S3). Conversely, in line with previously reported data, ${ }^{43}$ combination of IFN- $\alpha 2 a$ or IFN- $\alpha 2 b$ with sorafenib, a different protein kinase inhibitor (PKI) that inhibits the antiviral effects of IFN, resulted in antagonism (CI of 1.23 ; $95 \%$ credible interval (1.13-1.34) and $1.27,95 \%$ credible interval (1.16-1.38); online supplementary figure S1A,B and table S3), demonstrating that the observed synergies are specific for the combinations and not related to technical issues of the model. Calculation of $95 \%$ credible intervals indicates that the differences between CI values did not occur by chance (see online supplementary table S3). These data demonstrate that entry inhibitors enhance the antiviral activity of IFN- $\alpha$.

\section{Synergy in experimental design for treatment of HCV infection}

Finally, to explore whether synergy between DAAs or HTAs and entry inhibitors also occurs in experimental approach mimicking treatment of chronic infection, we used a well-established design of persistent infection. ${ }^{23}$ Similar to the prevention design shown before, combining DAAs or alisporivir with entry inhibitors also resulted in high synergy when compounds were added postinfection in chronically infected cells (figure 6) as well as in chronically infected DMSO-differentiated hepatoma cells ${ }^{26}$ (figure 7), which are more physiologically relevant than normal hepatoma cells. These data demonstrate the potential of combining DAAs or HTAs with entry inhibitors to improve their antiviral activity for the treatment of chronic hepatitis C.

\section{Entry inhibitors limit viral rebound from DAA therapy}

Using the cell culture model system for chronic HCV infection, we studied whether entry inhibitors limit viral rebound following discontinuation of DAA treatment. As shown in figure 8, treatment of persistently $\mathrm{HCV}$-infected cells with a wellcharacterised and recently FDA-approved protease inhibitor, simeprevir, resulted in a rapid reduction of viral load in a timedependent manner. However, an increase in viral load was observed following withdrawal of simeprevir. In contrast, the addition of an entry inhibitor (anti-CD81 mAb or erlotinib) at the time of simeprevir withdrawal allowed to further decrease the viral load, indicating that entry inhibitors limit viral rebound from DAA therapy. Cell viability test at the end of the 


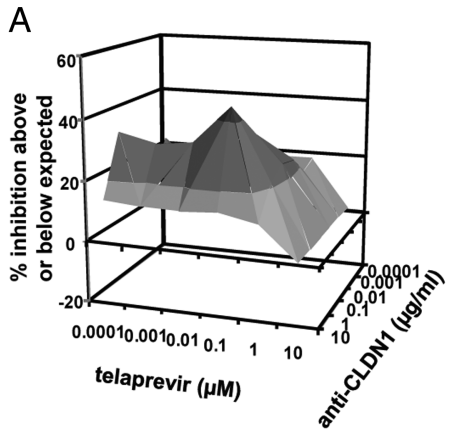

C

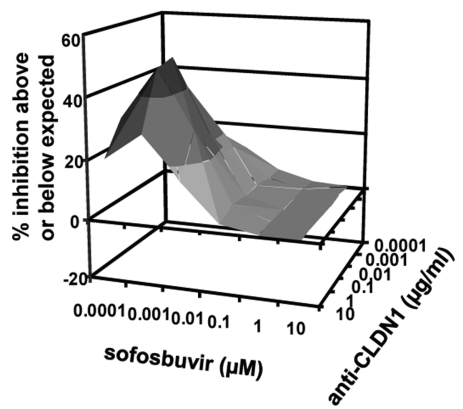

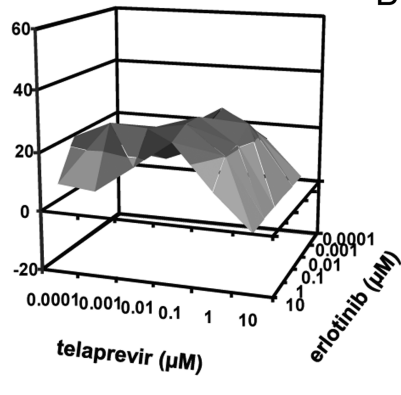

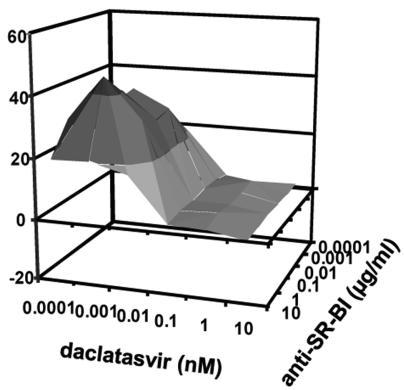

D

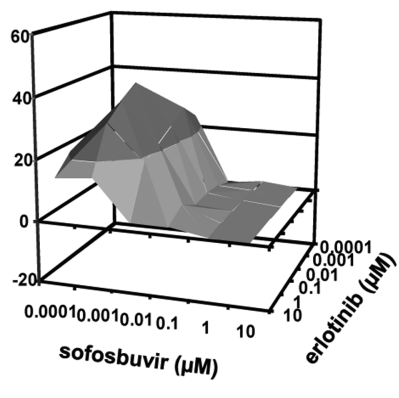

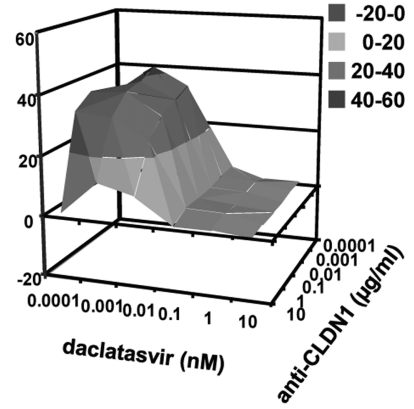

$-20-0$

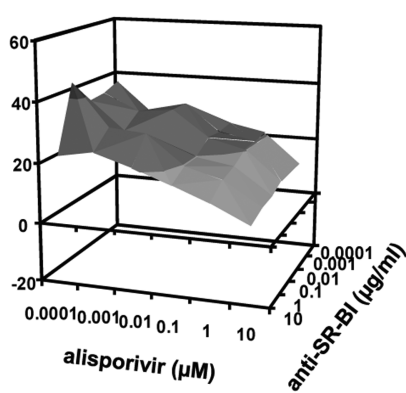

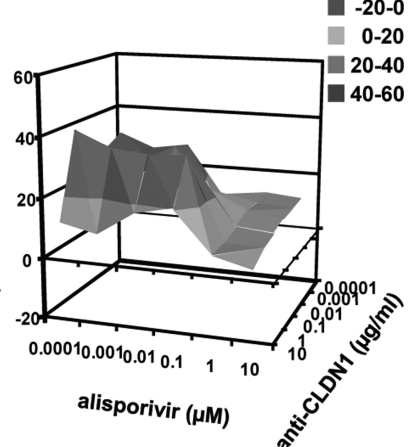

Figure 6 Combination of direct-acting antivirals (DAAs), host-targeting agents and entry inhibitors results in synergy in treatment of established HCV infection. Huh7.5.1 cells were infected for 5 days with HCVcc prior to treatment with DAAs or alisporivir and entry inhibitors as described in 'Materials and methods'. Synergy between (A) telaprevir and anti-CLDN1 mAb (left) or erlotinib (right), (B) daclatasvir and anti-SR-BI mAb (left) or anti-CLDN1 mAb (right), (C) sofosbuvir and anti-CLDN1 mAb (left) or erlotinib (right), (D) alisporivir and anti-SR-BI (left) or anti-CLDN1 mAb (right) was assessed using the Prichard and Shipman method. ${ }^{25}$

experiment demonstrated that the reduction of viral infection was not due to cytotoxicity (table 1D).

\section{Combination of entry inhibitors and DAAs in vivo}

To assess the relevance of combining an entry inhibitor and a DAA for treatment of HCV infection and provide experimental evidence for a synergistic effect of entry inhibitors and DAAs in vivo, we used human liver-chimeric uPA/SCID mice persistently infected with HCVcc (Jc1). Nine persistently infected mice were grouped randomly to receive either telaprevir monotherapy, anti-SR-BI mAb monotherapy, combination of telaprevir and anti-SR-BI mAb or the control treatment for 2 weeks as described in 'Materials and methods'. In line with previous reports, ${ }^{44}$ telaprevir only slightly reduced viral load of HCV genotype 2-infected mice, while anti-SR-BI mAb-treated mice showed a reduction of HCV RNA levels of approximately $1 \log _{10}$ at the end of the treatment. Interestingly, the combination of telaprevir and anti-SR-BI $\mathrm{mAb}$ resulted in a more potent reduction of viral load at each tested time point than the calculated sum of both monotherapies (at d10 HCV load for the control treatment is 6.86 $\pm 0.06 \log _{10}$; for telaprevir monotherapy $6.72 \pm 0.42 \log _{10}$; for anti-SR-BI $\mathrm{mAb} 6.03 \pm 0.54 \log _{10}$; for combination therapy in the responder mouse $3.71 \log _{10}$ ), reaching more than $2 \log _{10}$ in one of the mice after 10 days (figure 9A). One mouse treated with telaprevir and anti-SR-BI $\mathrm{mAb}$ did not respond to treatment (figure 9A). Stable levels of HA in the blood of mice from different treatment groups (figure 9B) suggested that their liver function was not affected by the treatment, indicating that telaprevir or/and anti-SR-BI mAb combination therapy did not result in major hepatotoxicity in vivo.
Absent toxicity of combinations in PHHs and hepatoma cells Noteworthy, the uncovered combinations did not exhibit any detectable toxicity in PHH nor Huh7.5.1 cells, neither in shortterm or long-term infection experiments (table 1). In contrast, anti-Fas antibody or the well-characterised kinase inhibitor flavopiridol resulted in easily detectable toxicity (table 1 ). The $50 \%$ cytotoxic concentrations $\left(\mathrm{CC}_{50}\right)$ of entry inhibitors in long-term experiments were more than 10 -fold or 100 -fold higher than the therapeutic concentrations used in treatment experiments (table 1C). Taken together, these data demonstrate that the uncovered combinations have a favourable safety profile in cell culture models and primary cells providing the rationale for their further development.

\section{DISCUSSION}

There is an unmet medical need for novel strategies for the prevention of HCV graft infection following LT, and a need to develop more efficient and better tolerated combination therapies for chronic infection for certain patient subgroups and patients with resistance. ${ }^{1}{ }^{2}$ Many DAAs are restricted to genotype 1 and their use in difficult-to-treat patients could be hindered by significant and potentially harmful drug-drug interactions. ${ }^{7}$ Among the most promising DAAs are polymerase and NS5A inhibitors, which demonstrated potent pan-genotypic antiviral activity with a high barrier for resistance when combined with SOC or RBV. ${ }^{45}{ }^{46}$ Nevertheless, in vivo emergence of resistant mutants conferring cross-resistance to polymerase inhibitors sofosbuvir and mericitabine has been described, ${ }^{47}$ and combination of daclatasvir with protease inhibitors was associated with significant viral breakthrough rates. ${ }^{3}{ }^{37}$ Recent phase III studies indicate that sofosbuvir and RBV had only limited efficacy against genotype 3 compared with SOC, with lowest 
A

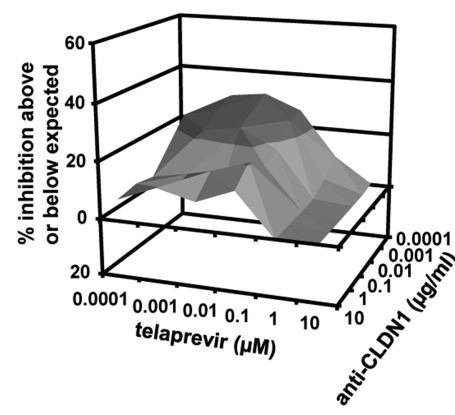

C

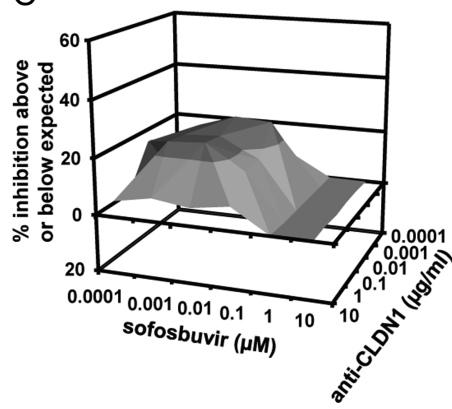

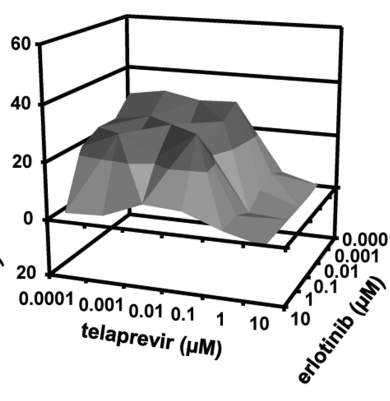

$\mathrm{B}$
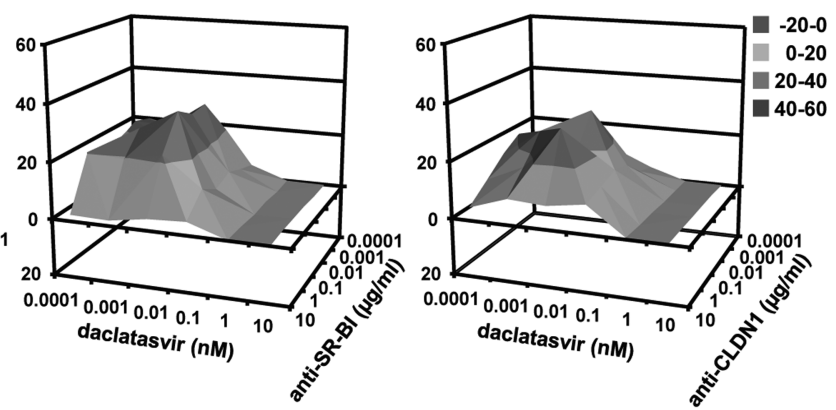

D

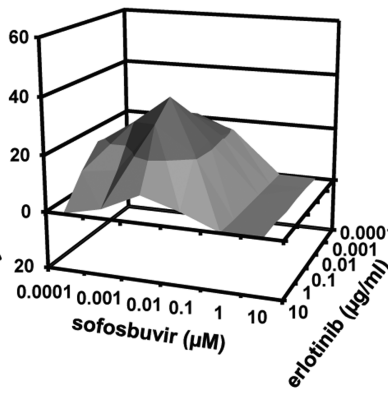

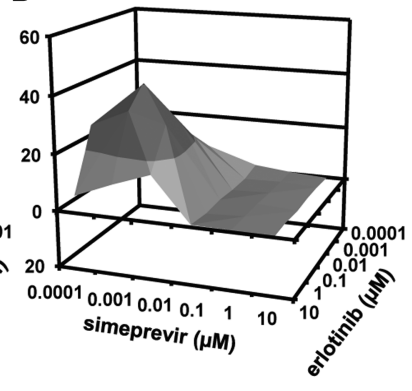

Figure 7 Synergistic effect of combining direct-acting antivirals and entry inhibitors in treatment of HCV infection using persistently infected DMSO-differentiated hepatoma cells. HCV-infected cell culture was established by transfecting RNA encoding wild-type HCV Luc-Jc1 into Huh7.5.1 cells. The cells were then differentiated in the presence of $1 \%$ DMSO for 5 days before treatment with the combinations of $(A)$ telaprevir +anti-CLDN1 mAb (left) or erlotinib (right), (B) daclatasvir+anti-SR-BI mAb (left) or anti-CLDN1 mAb (right), (C) sofosbuvir+anti-CLDN1 mAb (left) or erlotinib (right), (D) simeprevir+erlotinib (left) or anti-CLDN1 mAb (right). HCVcc infection was assessed by luciferase activity 5 days after treatment. Synergy was assessed using the Prichard and Shipman method. ${ }^{25}$

efficacy in cirrhotic patients. ${ }^{40} 41$ Thus, strong antiviral efficacy and high genetic barrier to resistance will remain key requirements for IFN-free regimens to avoid early treatment failure

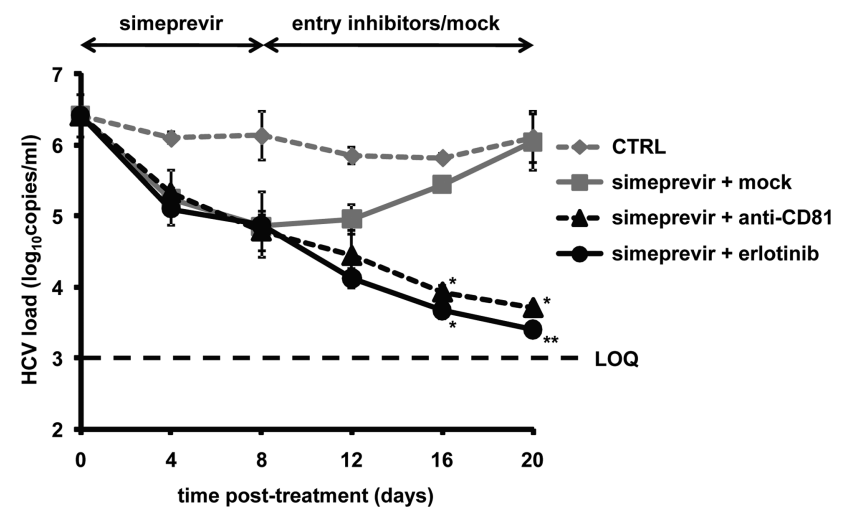

Figure 8 Entry inhibitors limit viral rebound from direct-acting antiviral therapy. Persistently HCV (JC1) infected and

DMSO-differentiated cells described in 'Materials and methods' were first treated with $500 \mathrm{nM}$ simeprevir for 8 days followed by incubation with either 1\% DMSO control medium (mock), $10 \mu \mathrm{g} / \mathrm{mL}$ anti-CD81 $\mathrm{mAb}$ or $10 \mu \mathrm{M}$ erlotinib sequentially for another 12 days. Cells maintained in 1\% DMSO throughout the experiment were used as control (CTRL). Viral load was assessed by HCV-specific RT-PCR every 4 days. The limit of quantification, indicated by a dashed line, was $10^{3}$ copies $/ \mathrm{mL}$. Means $\pm S D$ from a representative experiment performed in triplicate are shown. An asterisk indicates one out of three samples was HCV RNA negative; two asterisks indicate two samples were HCV RNA negative. and the optimal combination for defined patient groups and viral genotypes still needs to be defined.

To address the limitations of SOC and DAAs, we evaluated the antiviral effect of combining entry inhibitors with IFN- $\alpha$, DAAs or HTAs. Our results uncover novel combinations of entry inhibitors and IFN- $\alpha$, DAAs or HTAs highlighted by marked synergy in vitro (figures 1-7, online supplementary figure S1 and tables S1-S3). Antiviral activity of compounds in the HCVcc model correlates well with clinical antiviral activity in patients, ${ }^{36}$ and synergy was robust and significant at $\mathrm{IC}_{50}$, $\mathrm{IC}_{75}$ and $\mathrm{IC}_{90}$, at all concentrations tested and similar in experimental prevention and treatment designs. Furthermore, we also demonstrate evidence for a synergistic effect of the combination of an entry inhibitor with a DAA in vivo using the human liver-chimeric uPA/SCID mouse model (figure 9).

A challenge of current and future therapies remains the countering of the development of drug-resistant variants. ${ }^{1-3}$ Compared with the high variability of viral proteins targeted by DAAs, the variability of host factors targeted by HTAs is low. ${ }^{8}$ Therefore, host-targeting entry inhibitors may impose a higher genetic barrier to resistance than DAAs. Supplementary to this concept, we and others have shown that entry inhibitors potently inhibit highly infectious escape variants of HCV that are resistant to host neutralising antibodies. ${ }^{9} \quad 10 \quad 13-15 \quad 22$ Interestingly, the disease outcome for HIV-infected individuals has significantly improved with the development of antiretroviral drugs targeting different steps of the viral life cycle including viral entry. ${ }^{48}$ Although viral variants resistant to HIV entry inhibitors have been described, there is no evidence of crossresistance between different classes of antivirals. ${ }^{48}$ In contrast to HIV, co-receptor tropism/switch has not been described for $\mathrm{HCV}$ as a potential mechanism for viral escape and successful 
Table 1 Absent toxicity of combinations of compounds in Huh7.5.1 cells and primary human hepatocytes

\begin{tabular}{|c|c|c|c|c|c|}
\hline Compound 1 & Concentration & Compound 2 & Concentration & Relative Huh7.5.1 viability (\%) & Relative PHH viability (\%) \\
\hline \multicolumn{6}{|c|}{ (A) Cytotoxic effects of combination therapies on Huh7.5.1 cells and PHH after $48 \mathrm{~h}$} \\
\hline IFN- $\alpha 2 \mathrm{a}$ & $10 \mathrm{IU} / \mathrm{mL}$ & Anti-CLDN1 & $10 \mu \mathrm{g} / \mathrm{mL}$ & $106 \pm 11$ & $101 \pm 2$ \\
\hline IFN- $\alpha 2 b$ & $10 \mathrm{IU} / \mathrm{mL}$ & Anti-CLDN1 & $10 \mu \mathrm{g} / \mathrm{mL}$ & $108 \pm 15$ & $97 \pm 3$ \\
\hline Telaprevir & $10 \mu \mathrm{M}$ & Erlotinib & $10 \mu \mathrm{M}$ & $84 \pm 21$ & $93 \pm 5$ \\
\hline Boceprevir & $10 \mu \mathrm{M}$ & Anti-CLDN1 & $10 \mu \mathrm{g} / \mathrm{mL}$ & $94 \pm 8$ & $103 \pm 3$ \\
\hline Simeprevir & $10 \mu \mathrm{M}$ & Anti-CLDN1 & $10 \mu \mathrm{g} / \mathrm{mL}$ & $104 \pm 5$ & $97 \pm 4$ \\
\hline Danoprevir & $10 \mu \mathrm{M}$ & Anti-CLDN1 & $10 \mu \mathrm{g} / \mathrm{mL}$ & $91 \pm 12$ & $103 \pm 1$ \\
\hline Daclatasvir & $10 \mathrm{nM}$ & Anti-SR-BI & $10 \mu \mathrm{g} / \mathrm{mL}$ & $114 \pm 18$ & $101 \pm 2$ \\
\hline Mericitabine & $10 \mu \mathrm{M}$ & Anti-CD81 & $10 \mu \mathrm{g} / \mathrm{mL}$ & $131 \pm 22$ & $106 \pm 5$ \\
\hline Sofosbuvir & $10 \mu \mathrm{M}$ & Anti-SR-BI & $10 \mu \mathrm{g} / \mathrm{mL}$ & $95 \pm 15$ & $110 \pm 7$ \\
\hline Sofosbuvir & $10 \mu \mathrm{M}$ & Anti-CLDN1 & $10 \mu \mathrm{g} / \mathrm{mL}$ & $93 \pm 8$ & $97 \pm 5$ \\
\hline Sofosbuvir & $10 \mu \mathrm{M}$ & Dasatinib & $10 \mu \mathrm{M}$ & $89 \pm 14$ & $103 \pm 8$ \\
\hline Sofosbuvir & $10 \mu \mathrm{M}$ & Erlotinib & $10 \mu \mathrm{M}$ & $87 \pm 15$ & $101 \pm 4$ \\
\hline Anti-Fas & $10 \mu \mathrm{g} / \mathrm{mL}$ & & & & $16 \pm 2$ \\
\hline Compound 1 & Concer & & Compound 2 & Concentration & Relative Huh7.5.1 viability (\%) \\
\hline \multicolumn{6}{|c|}{ (B) Cytotoxic effects of combination therapies on Huh7.5.1 cells after 5 days } \\
\hline Telaprevir & $10 \mu \mathrm{M}$ & & Anti-CLDN1 & $10 \mu \mathrm{g} / \mathrm{mL}$ & $92 \pm 4$ \\
\hline Telaprevir & $10 \mu \mathrm{M}$ & & Erlotinib & $10 \mu \mathrm{M}$ & $89 \pm 3$ \\
\hline Daclatasvir & $10 \mathrm{nM}$ & & Anti-SB-BI & $10 \mu \mathrm{g} / \mathrm{mL}$ & $103 \pm 16$ \\
\hline Daclatasvir & $10 \mathrm{nM}$ & & Anti-CLDN1 & $10 \mu \mathrm{g} / \mathrm{mL}$ & $106 \pm 7$ \\
\hline Sofosbuvir & $10 \mu \mathrm{M}$ & & Anti-CLDN1 & $10 \mu \mathrm{g} / \mathrm{mL}$ & $93 \pm 2$ \\
\hline Sofosbuvir & $10 \mu \mathrm{M}$ & & Erlotinib & $10 \mu \mathrm{M}$ & $91 \pm 4$ \\
\hline Alisporivir & $10 \mu \mathrm{M}$ & & Anti-SR-BI & $10 \mu \mathrm{g} / \mathrm{mL}$ & $97 \pm 8$ \\
\hline Alisporivir & $10 \mu \mathrm{M}$ & & Anti-CLDN1 & $10 \mu \mathrm{g} / \mathrm{mL}$ & $108 \pm 6$ \\
\hline Flavopiridol & $10 \mu \mathrm{M}$ & & & & $20 \pm 6$ \\
\hline
\end{tabular}

(C) 50\% cytotoxic concentrations (CC 50 ) of entry inhibitors in Huh7.5.1 cells. Dose-dependent toxicity of entry inhibitors was measured using Prestoblue assay as described in Materials and methods. $\mathrm{CC}_{50}$ were calculated by regression analysis

Anti-CLDN1*

Anti-CD81*

Anti-SR-BI*

Erlotinibt

Dasatinibt

(D) Cytotoxic effects of combination therapies as described in figure 8. Cell viability was measured at the end of the experiment using Prestoblue assay as described in Materials and methods

$\begin{array}{lr}\text { Telaprevir+mock } & 97 \pm 10\end{array}$

$\begin{array}{lr}\text { Telaprevir+anti-CLDN1 } & 91 \pm 3\end{array}$

Telaprevir+erlotinib

$81 \pm 4$

Cytotoxic effects on Huh7.5.1 cells (A, B, C, D) and PHH (A) using the highest concentrations of each compound used in combination (IFN- $\alpha, 10$ IU/mL; DAAs, $10 \mathrm{nM}$ or $\mu$ M; alisporivir $10 \mu \mathrm{M}$; receptor-specific mAbs, $10 \mu \mathrm{g} / \mathrm{mL}$ and PKIs, $10 \mu \mathrm{M}$ ) were assessed by analysing the ability to metabolise MTT after $48 \mathrm{~h}(\mathrm{~A}, \mathrm{~B}), 5$ days (C), or 20 days (D) as described. ${ }^{23-32}$ Anti-Fas antibody $(10 \mu \mathrm{g} / \mathrm{mL})$ or flavopiridol $(10 \mu \mathrm{M})$ was used as a positive control of toxicity. Toxicity analyses of the most efficient combinations are shown. Data are presented as relative cell viability compared with PHH or Huh7.5.1 cells cultured in the absence of compounds or solvent $(=100 \%)$. Means \pm SD from one representative experiment performed in triplicate are shown.

*The stock concentration of the entry inhibitors was $2 \mathrm{mg} / \mathrm{mL}$.

†Erlotinib or dasatinib started to precipitate in the medium at the concentrations higher than $100 \mu \mathrm{M}$.

DAA, direct-acting antiviral; IFN, interferon; PHH, primary human hepatocyte; PKI, protein kinase inhibitor; SR-BI, scavenger receptor class B type I.

antiviral therapy can definitively eradicate HCV from infected patients. Combination of entry inhibitors with compounds targeting complementary steps of the viral life cycle may open a perspective to overcome antiviral resistance, allow shortening treatment schedules, lower the risk for adverse effects and reduce the doses of the single compounds.

Given that HTAs interfere with host targets, there is theoretically a greater risk of cellular toxicity than with DAAs. Host targets CD81, SR-BI, CLDN1 and EGFR described in this study are expressed in various tissues and play an important role in cell adhesion, lipid metabolism or signalling. Noteworthy, the large majority of licensed drugs in clinical use (eg, in cardiovascular, inflammatory disease or oncology) targets host proteins and side effects are not necessarily more pronounced than in drugs targeting the virus. ${ }^{8}$ Indeed, the EGFR inhibitor erlotinib, a clinically licensed drug for non-small-cell lung cancer, has a favourable safety profile and is well tolerated in lung cancer patients. ${ }^{49}$ Moreover, clinical licensed HIV host-targeting entry 

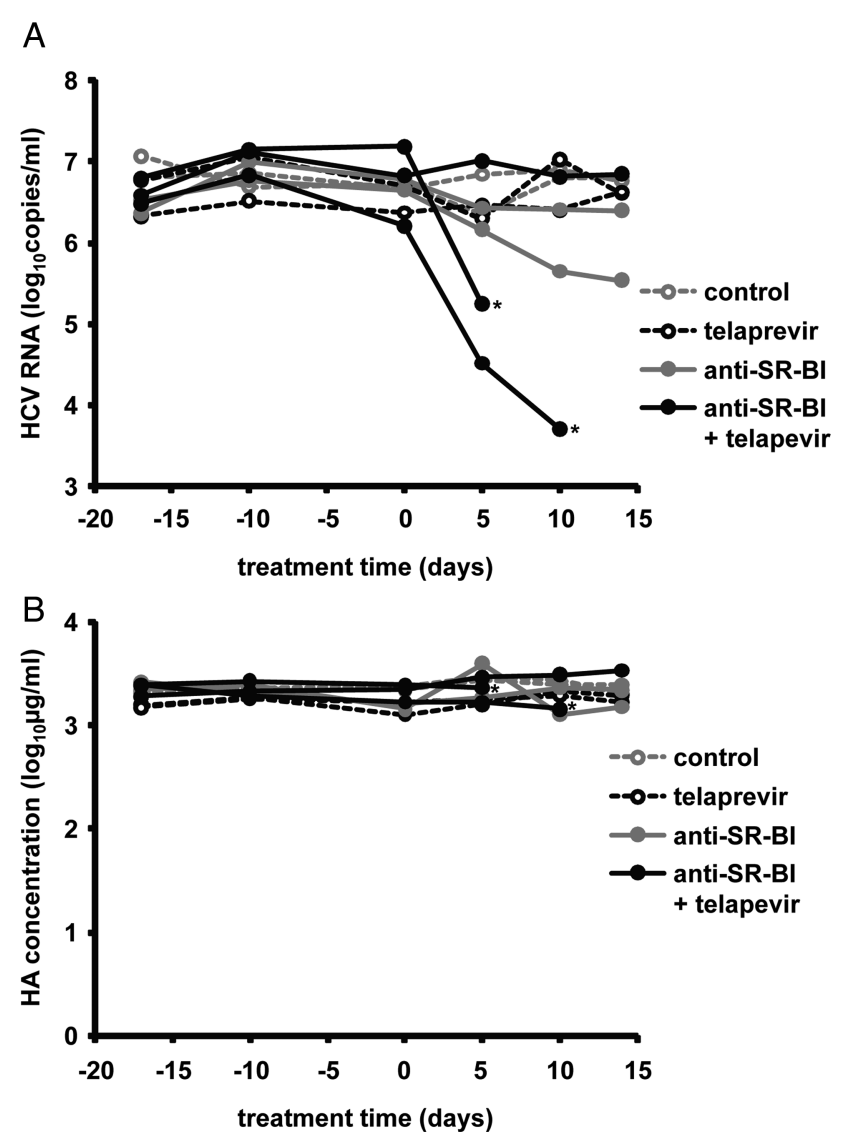

Figure 9 Effect of combination of an entry inhibitor and direct-acting antiviral on HCV infection in vivo. Human liver-chimeric UPA/SCID mice engrafted with primary human hepatocyte were inoculated with HCVCc (Jc1) 8 weeks before the experiment as described in 'Materials and methods'. Nine mice were grouped randomly into control group (two mice), telaprevir monotherapy group (two mice), scavenger receptor $B$ type I (SR-BI)-specific mAb (NK8-H5-E3) monotherapy group (two mice) and combination therapy group (three mice). Mice received telaprevir monotherapy (300 mg/kg PO BID), anti-SR-BI mAb monotherapy (500 $\mu \mathrm{g}$ IP twice a week), combination treatment of telaprevir and anti-SR-BI mAb or control treatments as described in 'Materials and methods'. Indicated by an asterisk, two mice from the group treated with combination of telaprevir and anti-SR-BI mAb had to be sacrificed before the end of the experiment due to bleeding and injury. (A) HCV RNA from mouse sera was measured by RT-PCR every $5-10$ days. Viral load of each individual mouse is shown. (B) Human albumin (HA) concentration in the blood of human liver-chimeric uPA/SCID mice. HA was measured during the treatment as described in 'Materials and methods'.

inhibitors do not necessarily display more adverse events than antiretroviral drugs. ${ }^{48}$ Nevertheless, safety is an important issue and needs to be carefully addressed for both DAAs and HTAs. Host-targeting antibodies will need to be humanised prior to clinical development.

A pan-genotypic, highly efficient, IFN-free regimen is the ultimate goal for HCV therapy. Compared with many DAAs that act in genotype-dependent manner, host-targeting entry inhibitors exhibit a broad pan-genotypic activity: examples include CLDN1-, ${ }^{22}$ SR-BI- ${ }^{14}{ }^{15}$ and CD81-specific ${ }^{16}{ }^{17} \mathrm{mAbs}$, ITX-5061, ${ }^{18}$ erlotinib, ${ }^{13}$ ezetimibe, ${ }^{12}$ flavonoids, ${ }^{19}{ }^{20}$ lectins, ${ }^{21}$ phosphorothioate oligonucleotides ${ }^{50}$ and silymarin. ${ }^{51}$ 52 Thus, combination of entry inhibitors with DAAs may define novel options for patients with non-genotype 1 infections and simplify treatment regimens.
Entry inhibitors are ideally suited for prevention of $\mathrm{HCV}$ liver graft infection. Currently, there is no option to protect HCV-negative grafts from reinfection while the clinical use of hepatitis B immune globulin (a well-characterised HBV entry inhibitor) in combination with nucleos(t)ide analogues has essentially eliminated HBV recurrence in LT patients. ${ }^{5}$ Since HCV entry is a key mechanism for liver graft infection, ${ }^{9}{ }^{10}$ the observed synergy between DAAs and entry inhibitors uncovers a promising opportunity for prevention of graft infection. The combination of host-targeting entry inhibitors with DAAs may be particularly attractive since the high variability of HCV has so far hampered the development of efficient cross-neutralising antienvelope antibodies. ${ }^{53}$

Interfering with HCV cell entry offers several targets at different steps of viral entry: blocking virus-target cell interaction during attachment, interfering with postbinding events such as CD81-CLDN1 associations or viral fusion. ${ }^{8}$ Interestingly, combination of different entry inhibitors, including CLDN1-specific $\mathrm{mAb}$ and kinase inhibitors, also showed synergy on HCV entry and infection (figure 5A). While CLDN1-specific antibodies and PKIs both interfere with CD81-CLDN1 coreceptor interactions, PKIs also interfere with glycoprotein-dependent viral fusion. ${ }^{13}$ This additional and complementary MOA on membrane fusion of PKIs is most likely responsible for the synergistic effect. This concept is confirmed by the finding that combination of anti-CD81 and anti-CLDN1 mAbs, which target a similar step in the viral entry process, only exhibits an additive effect (figure $5 \mathrm{~A})$. Thus, these results define novel combinations of entry inhibitors for prevention of graft infection.

Interestingly, two entry inhibitors erlotinib (targeting EGFR and CD81-CLDN1 co-receptor associations) and ITX-5061 (targeting HCV-SR-BI interactions) have reached clinical development to determine the safety and efficacy in patients with HCV infection (ClinicalTrials.gov identifier NCT01835938 and NCT01292824). Moreover, a significant number of compounds tested in this study are already FDA-approved for treatment of chronic HCV infection: telaprevir, boceprevir, sofosbuvir and simeprevir. Erlotinib and dasatinib have been approved for cancer treatment exhibiting a good safety profile. ${ }^{54}$ It will thus be interesting to investigate the synergistic effect of these drugs in patients with chronic hepatitis C. Taken into account the efficacy, safety, pharmacokinetics, stage of development combined with the synergy data of the various compounds (figures 1-7), our data suggest that combinations of simeprevir ${ }^{34}$ or sofosbuvir ${ }^{40}$ with erlotinib could be a starting point to assess synergy in randomised clinical trials. Combining sofosbuvir and anti-CLDN1 or anti-SR-BI mAb might be promising for prevention of liver graft infection following the clinical development of the monoclonal antibodies. Collectively, novel combinations based on synergy uncovered in this study may widen the therapeutic arsenal against HCV infection for prevention of liver graft infection, treatment of difficult-to-treat-patients and provide alternatives for patients with contraindications to particular compounds of SOC or future IFN-free regimens.

Acknowledgements We thank Dr R Bartenschlager (University of Heidelberg, Germany) for providing plasmids for production of HCV Vc, Dr FV Chisari (The Scripps Research Institute, La Jolla, CA) for the gift of Huh7.5.1 cells, Dr CM Rice (Rockefeller University, New York, NY), Dr JA McKeating (University of Birmingham, UK), Dr D Samuel (Inserm U785, Paul Brousse Hospital, Villejuif, France), Dr JM Pawlotsky (Inserm U955, Henri Mondor Hospital, Créteil, France), Dr T Berg (University Hospital, Leipzig, Germany), Dr RT Chung (Massachusetts General Hospital, Boston) and Dr M Dandri (University Medical Center, Hamburg, Germany) for helpful discussions. We thank L Heydmann, S Durand, T Wu and N Brignon (Inserm U1110) for excellent technical assistance. 
Contributors TFB initiated, designed and supervised research. FX, IF, CT, LM, RA, $E R, P L, J N, M B Z$ and TFB performed research. FX, IF, CT, LM, RA, ER, PL, JN, MBZ and TFB analysed data. NM and MS performed statistical analyses. FH and MD provided reagents. FX, IF, MBZ and TFB wrote the paper.

Funding This work was supported by Inserm, University of Strasbourg, the European Union (ERC-2008-AdG-233130-HEPCENT, INTERREG-IV-Rhin Supérieur-FEDER-Hepato-Regio-Net 2009 and 2012, EU FP7 HepaMab), ANRS (2011/132, 2012/239, 2012/318, 2013/108), Laboratoire d'excellence LabEx HEPSYS (Investissement d'Avenir; ANR-10-LAB-28), the Institut Hospitalo-Universitaire Mix-Surg and the Direction Générale de I'Offre de Soins (A12027MS). This work has been published under the framework of the LABEX ANR-10-LABX-0028_HEPSYS and benefits from a funding from the state managed by the French National Research Agency as part of the investments for the future programme. The group in Leuven was funded by a grant from the Fund for Scientific Research (FWO) (G.0728.09N) and KULeuven GOA 10/014.

Competing interests Inserm and the University of Strasbourg have filed patent applications on the synergy of interferons, direct-acting antivirals and entry inhibitors as well as SR-BI-specific antibodies, erlotinib, dasatinib for prevention and treatment of HCV infection. Inserm, University of Strasbourg and Genovac/Aldevron have filed a patent application for claudin-1-specific antibodies for prevention and treatment of HCV infection. TB serves as scientific advisor for Biotest, Vironexx and Gilead.

Ethics approval All animal experiments in this study were performed in accordance with local laws and ethical committee approval (AL/02/19/08/12 and AL/ 01/18/08/12)

Provenance and peer review Not commissioned; externally peer reviewed.

Open Access This is an Open Access article distributed in accordance with the Creative Commons Attribution Non Commercial (CC BY-NC 3.0) license, which permits others to distribute, remix, adapt, build upon this work non-commercially, and license their derivative works on different terms, provided the original work is properly cited and the use is non-commercial. See: http://creativecommons.org/ licenses/by-nc/3.0/

\section{REFERENCES}

1 Dabbouseh NM, Jensen DM. Future therapies for chronic hepatitis C. Nat Rev Gastroenterol Hepatol 2013;10:268-76.

2 Liang TJ, Ghany MG. Current and future therapies for hepatitis C virus infection. N Engl J Med 2013;368:1907-17.

3 Sarrazin C, Hezode C, Zeuzem S, et al. Antiviral strategies in hepatitis C virus infection. J Hepatol 2012;56(Suppl 1):S88-100.

4 Chung RT, Baumert TF. Curing chronic hepatitis C - the arc of a medical triumph. $N$ Engl J Med 2014;370:1576-8.

5 Crespo G, Marino Z, Navasa M, et al. Viral hepatitis in liver transplantation. Gastroenterology 2012;142:1373-83 e1.

6 Garg V, van Heeswijk R, Lee JE, et al. Effect of telaprevir on the pharmacokinetics of cyclosporine and tacrolimus. Hepatology 2011;54:20-7.

7 Charlton M. Telaprevir, boceprevir, cytochrome P450 and immunosuppressive agents - a potentially lethal cocktail. Hepatology 2011;54:3-5.

8 Zeisel MB, Lupberger J, Fofana I, et al. Host-targeting agents for prevention and treatment of chronic hepatitis C-perspectives and challenges. J Hepatol 2013;58:375-84.

9 Fafi-Kremer S, Fofana I, Soulier $\mathrm{E}_{\text {, et }}$ al. Viral entry and escape from antibody-mediated neutralization influence hepatitis $C$ virus reinfection in liver transplantation. J Exp Med 2010;207:2019-31.

10 Fofana I, Fafi-Kremer S, Carolla P, et al. Mutations that alter use of hepatitis C virus cell entry factors mediate escape from neutralizing antibodies. Gastroenterology 2012:143:223-33 e9.

11 Zona L, Lupberger J, Sidahmed-Adrar N, et al. HRas signal transduction promotes hepatitis $C$ virus cell entry by triggering assembly of the host tetraspanin receptor complex. Cell Host Microbe 2013;13:302-13.

12 Sainz B Jr, Barretto N, Martin DN, et al. Identification of the Niemann-Pick C1-like 1 cholesterol absorption receptor as a new hepatitis $C$ virus entry factor. Nat Med 2012:18:281-5.

13 Lupberger J, Zeisel MB, Xiao F, et al. EGFR and EphA2 are host factors for hepatitis $C$ virus entry and possible targets for antiviral therapy. Nat Med 2011;17:589-95.

14 Zahid MN, Turek M, Xiao F, et al. The postbinding activity of scavenger receptor class B type I mediates initiation of hepatitis C virus infection and viral dissemination. Hepatology 2013:57:492-504.

15 Lacek K, Vercauteren K, Grzyb K, et al. Novel human SR-BI antibodies prevent infection and dissemination of HCV in vitro and in humanized mice. $J$ Hepatol 2012;57:17-23.

16 Fofana I, Xiao F, Thumann C, et al. A novel monoclonal anti-CD81 antibody produced by genetic immunization efficiently inhibits Hepatitis $C$ virus cell-cell transmission. PloS One 2013;8:e64221.

17 Meuleman P, Hesselgesser J, Paulson M, et al. Anti-CD81 antibodies can prevent a hepatitis C virus infection in vivo. Hepatology 2008;48:1761-8.
18 Syder AJ, Lee $\mathrm{H}$, Zeisel MB, et al. Small molecule scavenger receptor BI antagonists are potent HCV entry inhibitors. J Hepatol 2011;54:48-55.

19 Haid S, Novodomska A, Gentzsch J, et al. A plant-derived flavonoid inhibits entry of all HCV genotypes into human hepatocytes. Gastroenterology 2012;143:213-22.e5.

20 Calland N, Albecka A, Belouzard S, et al. (-)-Epigallocatechin-3-gallate is a new inhibitor of hepatitis C virus entry. Hepatology 2012;55:720-9.

21 Meuleman P, Albecka A, Belouzard S, et al. Griffithsin has antiviral activity against hepatitis C virus. Antimicrob Agents Chemother 2011;55:5159-67.

22 Fofana I, Krieger SE, Grunert F, et al. Monoclonal anti-claudin 1 antibodies prevent hepatitis $C$ virus infection of primary human hepatocytes. Gastroenterology 2010;139:953-64, 64 e1-4.

23 Lupberger J, Duong FH, Fofana I, et al. Epidermal growth factor receptor signaling impairs the antiviral activity of interferon-alpha. Hepatology 2013;58:1225-35.

24 Zhao L, Wientjes MG, Au JL. Evaluation of combination chemotherapy: integration of nonlinear regression, curve shift, isobologram, and combination index analyses. Clin Cancer Res 2004;10:7994-8004.

25 Prichard MN, Shipman C Jr. A three-dimensional model to analyze drug-drug interactions. Antiviral Res 1990;14:181-205.

26 Bauhofer O, Ruggieri A, Schmid B, et al. Persistence of HCV in quiescent hepatic cells under conditions of an interferon-induced antiviral response. Gastroenterology 2012;143:429-38 e8.

27 Pietschmann T, Zayas M, Meuleman $\mathrm{P}$, et al. Production of infectious genotype $1 \mathrm{~b}$ virus particles in cell culture and impairment by replication enhancing mutations. PLoS Pathog 2009:5:e1000475.

28 Mercer DF, Schiller DE, Elliott JF, et al. Hepatitis C virus replication in mice with chimeric human livers. Nat Med 2001;7:927-33.

29 Wyles DL, Kaihara KA, Vaida F, et al. Synergy of small molecular inhibitors of hepatitis $C$ virus replication directed at multiple viral targets. J Virol 2007:81:3005-8.

30 Jacobson IM, McHutchison JG, Dusheiko G, et al. Telaprevir for previously untreated chronic hepatitis C virus infection. N Engl J Med 2011;364:2405-16.

31 Zeuzem S, Andreone P, Pol S, et al. Telaprevir for retreatment of HCV infection. N Engl J Med 2011;364:2417-28.

32 Bacon BR, Gordon SC, Lawitz E, et al. Boceprevir for previously treated chronic HCV genotype 1 infection. N Engl J Med 2011;364:1207-17.

33 Poordad F, McCone J Jr, Bacon BR, et al. Boceprevir for untreated chronic HCV genotype 1 infection. N Engl J Med 2011;364:1195-206.

34 Reesink HW, Fanning GC, Farha KA, et al. Rapid HCV-RNA decline with once daily TMC435: a phase I study in healthy volunteers and hepatitis $C$ patients. Gastroenterology 2010;138:913-21.

35 Gane EJ, Roberts SK, Stedman CA, et al. Oral combination therapy with a nucleoside polymerase inhibitor (RG7128) and danoprevir for chronic hepatitis C genotype 1 infection (INFORM-1): a randomised, double-blind, placebo-controlled dose-escalation trial. Lancet 2010:376:1467-75.

36 Gao M, Nettles RE, Belema M, et al. Chemical genetics strategy identifies an HCV NS5A inhibitor with a potent clinical effect. Nature 2010;465:96-100.

37 Lok AS, Gardiner DF, Lawitz E, et al. Preliminary study of two antiviral agents for hepatitis C genotype 1. N Engl J Med 2012:366:216-24.

38 Chayama K, Takahashi S, Toyota J, et al. Dual therapy with the nonstructural protein $5 \mathrm{~A}$ inhibitor, daclatasvir, and the nonstructural protein 3 protease inhibitor, asunaprevir, in hepatitis $\mathrm{C}$ virus genotype $1 \mathrm{~b}$-infected null responders. Hepatology 2012;55:742-8.

39 Gane EJ, Stedman CA, Hyland RH, et al. Nucleotide polymerase inhibitor sofosbuvir plus ribavirin for hepatitis C. N Engl J Med 2013:368:34-44.

40 Lawitz E, Mangia A, Wyles D, et al. Sofosbuvir for previously untreated chronic hepatitis C infection. N Engl J Med 2013;368:1878-87.

41 Jacobson IM, Gordon SC, Kowdley KV, et al. Sofosbuvir for hepatitis C genotype 2 or 3 in patients without treatment options. N Engl J Med 2013;368:1867-77.

42 Flisiak R, Feinman SV, Jablkowski M, et al. The cyclophilin inhibitor Debio 025 combined with PEG IFNalpha2a significantly reduces viral load in treatment-naive hepatitis C patients. Hepatology 2009;49:1460-8.

43 Himmelsbach $\mathrm{K}$, Hildt $\mathrm{E}$. The kinase inhibitor Sorafenib impairs the antiviral effect of interferon alpha on hepatitis C virus replication. Eur J Cell Biol 2013:92:12-20.

44 Shi N, Hiraga N, Imamura M, et al. Combination therapies with NS5A, NS3 and NS5B inhibitors on different genotypes of hepatitis $C$ virus in human hepatocyte chimeric mice. Gut 2013:62:1055-61.

45 Lawitz E, Lalezari JP, Hassanein T, et al. Sofosbuvir in combination with peginterferon alfa-2a and ribavirin for non-cirrhotic, treatment-naive patients with genotypes 1, 2, and 3 hepatitis C infection: a randomised, double-blind, phase 2 trial. Lancet Infect Dis 2013;13:401-8.

46 Kowdley KV, Lawitz E, Crespo I, et al. Sofosbuvir with pegylated interferon alfa-2a and ribavirin for treatment-naive patients with hepatitis $C$ genotype- 1 infection (ATOMIC): an open-label, randomised, multicentre phase 2 trial. Lancet 2013:381:2100-7

47 Tong $X$, Le Pogam S, Li L, et al. In vivo emergence of a novel mutant L159F/ L320F in the NS5B polymerase confers low-level resistance to the HCV polymerase inhibitors mericitabine and sofosbuvir. J Infect Dis 2014;209:668-75. 
48 Henrich TJ, Kuritzkes DR. HIV-1 entry inhibitors: recent development and clinical use. Curr Opin Virol 2013;3:51-7.

49 Shepherd FA, Rodrigues Pereira J, Ciuleanu T, et al. Erlotinib in previously treated non-small-cell lung cancer. N Engl I Med 2005;353:123-32.

50 Matsumura T, Hu Z, Kato T, et al. Amphipathic DNA polymers inhibit hepatitis C virus infection by blocking viral entry. Gastroenterology 2009;137:673-81.

51 Wagoner J, Negash A, Kane OJ, et al. Multiple effects of silymarin on the hepatitis C virus lifecycle. Hepatology 2010;51:1912-21.
52 Marino Z, Crespo G, D'Amato M, et al. Intravenous silibinin monotherapy shows significant antiviral activity in $\mathrm{HCV}$-infected patients in the peri-transplantation period. J Hepatol 2013;58:415-20.

53 Chung RT, Gordon FD, Curry MP, et al. Human monoclonal antibody MBL-HCV1 delays HCV viral rebound following liver transplantation: a randomized controlled study. Am J Transplant 2013;13:1047-54.

54 Cataldo VD, Gibbons DL, Perez-Soler R, et al. Treatment of non-small-cell lung cancer with erlotinib or gefitinib. N Engl J Med 2011;364:947-55. 